\title{
Fire retardant for expansion and linear joints in buildings and tunnels
}

\author{
Vasiliy Prusakov ${ }^{1}$, Marina Gravit $^{2}$, Yana Simonenko ${ }^{2 *}$, Anna Minnullina ${ }^{3}$ and Alexandra \\ Artyukhina $^{4}$ \\ ${ }^{1}$ LTD PROMIZOL Office 215, 2CPticefabrika St., Tomilino, Lyubertsy district of Moscow region, \\ 140073, Russia \\ ${ }^{2}$ Peter the Great St. Petersburg Polytechnic University, 29 Politekhnicheskaya St., St. Petersburg, \\ 195251, Russia \\ ${ }^{3}$ Tyumen Industrial University, Volodarskogo str., 38, Tyumen, 625000, Russia \\ ${ }^{4}$ Volgograd State Medical University,1, Pavshikh Bortsov Sq., 400131,Volgograd, Russia
}

\begin{abstract}
The review of fire-prevention barriers of deformation seams both foreign, and domestic manufacturers is provided in article. It is shown that the fire-prevention barriers which are specially developed for application in deformation seams, guaranteed working at compression, stretching and shift of a seam are applied to protection of deformation seams at the fire it is established that production of innovative fireproof materials is one of the main objectives of fire safety, it and ways of consecutive transformation of the idea to the goods passing stages of researches, design developments, productions and realization in projects of civil and industrial function of buildings. The prime purpose - to pick up the complex decision providing the maximum satisfaction of requirements when performing fireproof works on protection of a deformation seam at impact of the fire.
\end{abstract}

\section{Introduction}

Buildings of irregular architectural shapes and big extent are subject to deformations under the influence of fluctuations of temperature of external air, uneven sedimentation of soil of the basis, the seismic phenomena and other reasons. For prevention of cracks provide the deformation seams cutting the building on compartments in the bearing and protecting designs. The correct design, the device and execution of deformation seams are important at construction as given the chance to provide long service life and fire resistance of the main bearing and protecting structures of buildings, internal and external finishing. Standard requirements to the device and technical indicators of deformation seams don't exist now and as deformation seams are elements of the bearing and protecting designs, their fire resistance decides in a complex on other elements of fire-prevention barriers, use and application is regulated by standards of the Russian federal legislation. Special fire-prevention barriers which establish in deformation seams are applied to increase in the general fire resistance of a design.

\footnotetext{
*Corresponding author: YannaSimnna98@mail.ru
} 
According to the Ministry of Emergency Situations for last year, about 140 thousand fires occurred in Russia, 35 thousand were destroyed and 88 thousand buildings were damaged [1]. The fire resistance of a building, one of the classification characteristics, is calculated at the design stage, and represents an important stage in the measures to ensure fire safety [2 5]. The conjunctions between the enclosing structures of the building, to which fire safety requirements are presented, are divided into deformation (changing their geometric dimensions under the influence of any factors) and linear or construction (do not change their geometric dimensions). Deformation seams allow multi-storey and multi-section buildings to resist various loads throughout the life of the plant without reducing the bearing capacity of structures. Such impacts can arise from various factors, such as seismic activity, uneven soil density, temperature drop of the environment, increased loads.

Depending on the most typical loads, the expansion joints can be divided into 4 types [5]:

1) Temperature seams permeate the structure from top to bottom - from the floor to the roof, but they do not affect the foundation. Allow monolithic materials to freely contract and expand in the event of temperature changes.

2) Sedimentary seams divide the building along the entire height, that is, from the foundation to the roof, to avoid dangerous deformations due to uneven deformation of the ground.

3) Shrink seams are used in monolithic construction. Concrete, hardening, settles extremely unevenly, this leads to the creation of internal stress and, as a consequence, to the formation of cracks.

4) Anti-seismic seams are actively used in seismically active regions.

To the expansion joints, certain fire resistance requirements apply, as well as to floors, walls and partitions, which are determined in accordance with the normative documentation on fire safety of the building structure as a whole. Separate requirements for fire protection for the device of expansion joints in the Russian legislation does not exist, their fire resistance is determined in combination with other elements of the construction [6-8].

In the foreign and Russian systems of regulatory documents that establish the requirements for expansion joints, test methods and principles for the classification of fire protection means for building structures, there are significant differences, so the study of these documents, in particular, the conduct of a comparative analysis, is now a necessary part general process in the field of technical regulation in the Russian Federation aimed at changing the national system of standardization and integration with other systems European and the international community $[9,10]$.

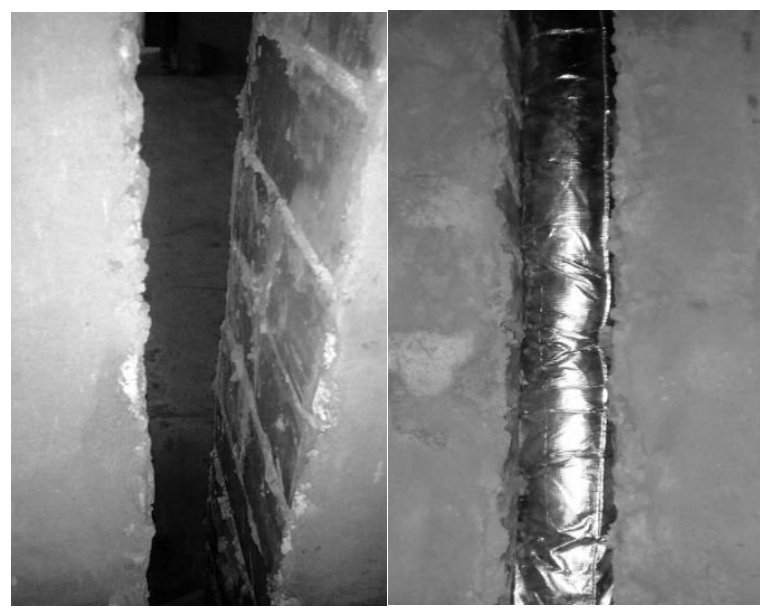

Fig. 1. Deformation seam without a fire barrier (right) and with a deformation barrier installed (left). 


\section{Research objective}

The purpose of this study is to examine the types of expansion joints and to study the use of fireproof sealing for expansion joints - materials (products) that are installed in horizontal and vertical expansion joints of monolithic and prefabricated iron-concrete structures of buildings and structures for various purposes and ensure non-propagation of a fire and its localization for the required time parameter.

Proper design, construction and installation of expansion joints are of great importance in construction, since they provide the opportunity to provide a long service life of the main load-bearing and enclosing structures of buildings, as well as elements of internal and external decoration. Structural seams are elements of junctions of building structures, such as walls, partitions and ceilings, and for them there are requirements for fire resistance. In accordance with Art. 88 123-FZ [6] the places of conjugation of fire walls, ceilings and partitions with other enclosing structures of a building, structure, fire compartment shall have a fire resistance limit not less than the limit of fire resistance of associated obstacles [11]. This requirement applies to all structures with standardized fire resistance limits. The main difficulty is that the use of common non-combustible materials is impossible due to the dynamic work of the expansion joints (compression, stretching, shear), which leads to accelerated wear of such non-combustible materials $[12,13]$.

For the protection of expansion joints in case of fire, the types of special fire-resistant equipment designed for use in expansion joints are used. Such designs (products) perform their functions and retain all fire-prevention characteristics, both during compression of the seam and during its stretching. And if, for example, mineral wool, installed in its pure form in the seam, while compressing the seam will still retain some protective properties, then under tension-shear seams, no serious protective function can be said. Only mineral wool, as a structural element of shielding the deformation seam from fire, according to the authors, will not withstand the tests under conditions simulating the work of the expansion joint. Analysis and study of fire-hazardous properties of building materials, assessment of the "behavior" of structures in a fire, calculation of the strength and stability of buildings with fire exposure - all this makes it possible to develop and offer consumers high-efficiency methods of fire protection of structural elements [14-17].

Among the leading manufacturers of fire protection systems for expansion joints, mention should be made of Veda-France, Hilti, Ogneza, Promat, LTD PROMIZOL.

Fire resistant fillings are installed to compensate for possible changes in the width of the seam from the original width to the horizontal and vertical expansion joints of monolithic and prefabricated reinforced concrete structures of buildings and structures for various purposes, as well as to the gaps between the end of the vertical walls and the interstorey.

\section{Materials and Methods}

Consider in more detail the installation of products for the protection of expansion joints using the example of products manufactured by LTD PROMIZOL

The product "PROMIZOL-Shov-Sh150 / 240" type "cord" provides fire protection of expansion joints with a width of up to $100 \mathrm{~mm}$ and fire resistance up to EI 240 to ensure a given fire resistance. Installation of similar products intended for fireproofing of expansion joints $30 \mathrm{~mm}$ wide or smaller, the minimum depth of sealing is critical from the heated side, $50 \mathrm{~mm}$ or more.

The fire protection of the expansion joint over $100 \mathrm{~mm}$ wide is produced by the product "PROMI-ZOL-SHOV-P150 / 240", the "pillow" type, which is also designed to provide fire resistance up to EI 240. Schematically, the differences between fireproof joints of expansion 
joints of the type "PROMIZOL- -SH150 / 240 "type" cord "and" PROMIZOL-Shov-P150 / 240 "type of" pillow "are shown in Fig. 2,3.

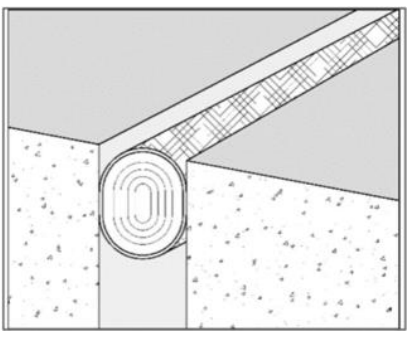

Fig. 2. Fire protection of expansion joint with width less than $100 \mathrm{~mm}$ by firestop cord PROMIZOLSHOV-SH150/240

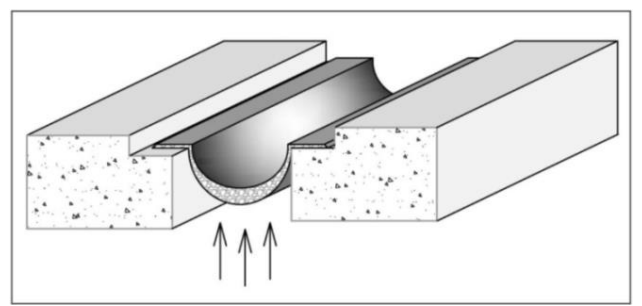

Fig. 3. Fire protection of expansion joint with width more than $100 \mathrm{~mm}$ by firestop cushion PROMIZOLSHOV-SH150/240

In order to understand the behavior of the expansion joint and its properties under mechanical influences during the operation, samples were tested in full size (diameter 80 $\mathrm{mm}$, length $1000 \mathrm{~mm}$ ) on testing equipment, and specified technical modes, according to Spec. TU 23.99.19-00--2017 "Tests on the mechanical strength of the fire barrier to protect the deformation seam developed by LTD PROMIZOL. The test procedure is to repeatedly change the design size of the simulator of the expansion joint with the installed test product. The tester step-by-step increases the load in the given direction (compression, stretching or shear) until the appearance of characteristic damages or irreversible changes in the product. The tests showed that PROMIZOL-Seam has the following stable deformation characteristics: compression $60 \%$, stretching $40 \%$, shift $45 \%$, at which there are no mechanical damage and permanent deformation. Positive results were obtained in the cyclicity test: compression-expansion and shear. This technique of mechanical testing of the filling of expansion joints can be used to test any shell products intended for sealing expansion joints. For embedding, which by the principle of filling is simply used for stamping (stamping) of the seam, there is no physical sense in checking their deformation properties, due to the absence of a given uniformity of filling and the absence of controlled boundaries. What is the "weak spot" of this method, because of the lack of control over the density of "zachekanka" after the effects of deformations.

Fireproof aggregates of LTD PROMIZOLare one of the few systems that were developed specifically for operation in expansion joints and the main task of the developers was to ensure non-propagation of fire, even with the opening of the joint by $50 \%$. For example, the fire barrier "PROMIZOL-Shov-Sh150 / 240" of the "cord" type is designed to protect the expansion joint with a width of 20 to $100 \mathrm{~mm}$, with the recommended product diameter from 28 to $140 \mathrm{~mm}$, providing a fire resistance rating of EI $150-240$. A special role in achieving the declared deformation and fire-resistant characteristics is played by the preliminary compression of the product, which depends on the expected width of the deflected expansion joint.

The production of the fire barrier "PROMIZOL-SHOV-SH (P) 150/240" uses a highquality basaltic ultrafine fiber, located in a special way. Control over the content of solid nonfibrous inclusions with a size exceeding $0.25 \mathrm{~mm}$, not exceeding $10 \%$ of the total share of the aggregate, allows to guarantee the work of the product for a long time, commensurate with the period of operation of the designed buildings. In addition, the fire protection system "PROMIZOL-Shov-Sh150 / 240" includes a special fire-retardant adhesive, the consumption of which depends on the diameter of the cord. The fire resistance test (EI) was carried out in accordance with GOST 30247.1, as the fire resistance of the enclosing structure, in which the 
design width was provided for the entire length of the furnace, and in which, according to the work schedule, a "PROMIZOL" Shov-Sh150 / 240. The tests showed that the limits of fire resistance (EI) depending on the width of the fire barrier "PROMIZOL-Shov-P150 / 240" of the "pillow" type with a width of the expansion joint of $150 \mathrm{~mm}$ with the recommended size of the fire barrier $220 \mathrm{~mm}$ is from 150 to 240 minutes; with a joint width of $400 \mathrm{~mm}$ and a product size of $570 \mathrm{~mm}$ - from 150 to 240 minutes.

Table 1. Main performance characteristics «Promizol-Shov-Sh150/240»:

\begin{tabular}{|r|c|c|}
\hline \multicolumn{1}{|c|}{ No } & Options & Parameter value \\
\hline 1 & Densityofthemainmaterialused & $75 \mathrm{~kg} / \mathrm{m} 3$ \\
\hline 2 & $\begin{array}{c}\text { Thermal conductivity, } \mathrm{W}(\mathrm{m} \cdot \mathrm{K}), \text { not more } \\
\text { at a temperature of }(20 \pm 5)^{\circ} \mathrm{C}\end{array}$ & 0,04 \\
\hline 3 & Water absorption for 24 hours by volume & Not more than $2 \%$ \\
\hline 4 & Resistant to mold and fungi & Yes \\
\hline 5 & Humidity, $\%$ by weight, no more than & 0,5 \\
\hline 6 & Seismicstability & Yes \\
\hline 7 & Vibrationresistance & Yes \\
\hline 8 & Elasticity & Yes \\
\hline 1 & Resistance to most chemicals \\
aggressive substances & $30-40$ yearsold \\
\hline 1 & Minimumservicelife & Yes \\
\hline 1 & Repairability & \\
\hline
\end{tabular}

To prevent the penetration of fire, through the joints of barriers in the installation of objects, when processing the ends of fire barriers "PROMIZOL-SHOV-SH (P) 150/240" uses a special fire retardant mesh.

For fire protection of linear seams, the fire barrier "PROMIZOL-Shov" is used. The principle of fire protection of linear seams is analogous to the fire protection of expansion joints, but the material is less critical to multiple changes in linear dimensions. Typical solutions for the use of the fire barrier "PROMIZOL-Shov-Sh150 / 240" are shown in Fig. 4.

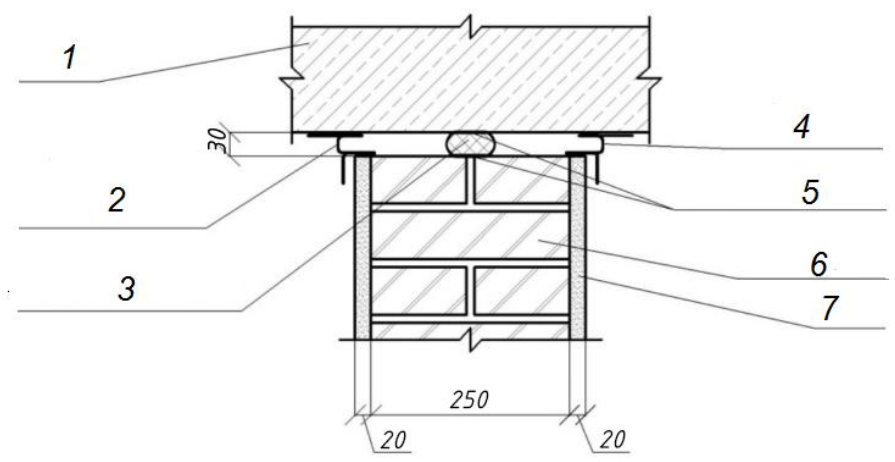

Fig. 4. The structure of an expansion joint [expansion joint?] in width of $30 \mathrm{~mm}$ with limit of fire resistance EI 240, where: 1 - reinforced concrete floor slab; 2, 4 - molding for expansion joint; 3 firestop cover PROMIZOL-SHOV-SH150/240-50; 5 - glue base PROMIZOL-K; 6 - facing

Thus, fireproof sealing for expansion joints is a complex of materials and measures that prevent the penetration of open fire, radiant energy and combustion products through the expansion joints, and include: 
1) fire-resistant sealing is not only a non-combustible material, it is a technologically complex structure that operates under conditions of cyclic deformation;

2) Adhesive compound for fixing the seal to adjacent construction structures, includes adhesive compositions and mounting kits (perforated tapes and fasteners);

3) Materials for fire protection joints themselves. Typically, for a typical construction, fittings of a certain length are produced, usually $2.0 \mathrm{~m}$. To ensure the fire resistance of joints, the material is additionally applied;

4) Installation technology;

5) Conducting mechanical tests confirming the possibility of preserving the properties of the seal during operation, including during subsequent fire tests (after mechanical tests).

\section{Results and discussion}

To protect the expansion joints in case of fire, a fire-resistant seal is applied, specially designed for use in expansion joints, which is guaranteed to work with cyclic deformations of compression, stretching and shearing of the seam, and this is their main difference.

Based on the research of fire-protective technologies for expansion joints [18-28], the authors determined the basic requirements for deformation (mechanical) and fire-protective properties of structures (products) intended for fire protection of the expansion joint providing complex performance characteristics.

Structures (products) intended for fire protection of the expansion joint should provide:

- stable own mechanical tensile strength not less than $40 \%$. After the test, the structure (article) should not have mechanical damages and deformation of the filler;

- stable own mechanical compressive strength not less than $50 \%$. After the test, the structure (article) should not have mechanical damages and deformation of the filler;

- stable deformation (mechanical) shear strength not less than $20 \%$. After the test, the structure (article) should not have mechanical damages and deformation of the filler;

- Preservation of elastic properties at the manufacturer's declared maximum impact with stretching-compression-shearing on the product for at least 100 cycles. After the test, the structure (article) should not have any mechanical damage and deformation of the filler;

- the manufacturer's declared fire resistance (EI), tested with at least $20 \%$ expansion and shear from the design width of the expansion joint, including after mechanical tests.

The listed parameters are recommended to be presented in the technical documentation of the manufacturer of the construction (product) of the fire-resistant seal for the expansion joint. All designs (products), whose parameters do not meet the requirements indicated above, should be referred to products for the protection of non-expansion joints.

When using other fillers for fireproof filling of the joint, it is recommended that the above requirements be met using material that provides deformation characteristics, both in the compression of the joint and during its stretching and shearing during the entire period of the intended use of the building. Particular attention should be paid to the technology of interface between the structures (products) of fire barriers when they are installed in deformation seams along the entire length, which is guaranteed to prevent the appearance of technological gaps and voids.

\section{References}

1. Ministry of the Russian Federation for Civil Defense Affairs, Emergencies of Elimination of Consequences of Natural Disasters [Electronic resource] Statistics of fires for (2016)

2. I.A.Osipov, O.A. Zybina, Engineering and construction magazine, 8(52) (2014) 
3. Ye.V. Goleva, A.V. Starikov, Actual problems of socio-humanitarian and scientific and technical knowledge, 1(6) (2016)

4. M. Qianli, G. Wei, Procedia Engineering. 45 (2012)

5. F.Voldrzhikh, Deformatsionnyye shvy $\mathrm{v}$ konstruktsiyakh i nazemnykh zdaniyakh (Deformation seams in structures and land buildings) Moscow. Stroyizdat, 224 p. (1978)

6. Technical regulations on the requirements of fire safety, Russian Federal Law of 22.07.2008. No 123-FZ (Edited on July 29, 2017)

7. V.A. Makovey, Emergencies: industrial and environmental safety, 1(25) (2016)

8. V.A. Makovey Emergencies: industrial and environ-mental safety, 4(24) (2015)

9. T.Yu. Yeremina, M.V. Gravit, Yu.N., Architecture and construction of Russia, 9 (2012)

10. M.V. Gravit, .Standards and Quality, 2 (919) (2014)

11. V.A. Kazakova, A.G. Tereshchenko, E.S. Nedviga, Construction of unique buildings and structures, 3(18) (2014)

12. H. Takabatake, M. Yasui, Y. Nakagawa, A. Kishida, Relaxation method for pounding action between adjacent buildings at expansion joint. Earthquake engineering \& structural dynamics, 43 (2014)

13. R.B. Orlovich, S.S. Zimin, N.M. Rubtsov, Construction and reconstruction, 3(53) (2014)

14. N.A. Ilyin, A.I. Bityutsky, A.P. Shepelev, E.I. Frolova, S.V. Esmont, Urban planning and architecture, 4(8) (2012)

15. E.E. Kiryukhantsev, V.N. Ivanov, Technologies of technospheric safety, 4(50) (2013)

16. Yu.V. Krivtsov, D.G. Pronin, Herald of SIC Construction, 11 (2014)

17. N.A Ilyin, Modern high technology, 1 (2009)

18. N.A. Gordeyev, G.N Godunova, Fire and explosion, T. 26, 4 (2017)

19. V.I. Pletnev, S.T. Nguyen, Herald of Civil Engineers, 1 (2011)

20. T. Saknite, D. Serdjuks, V. Goremikins, L. Pakrastins, N.I. Vatin, Engineering and construction journal, 4(64) (2016)

21. I.S. Dzyuba, N.I. Vatin, V.D. Kuznetsov, Engineering and construction magazine, 1 (2008)

22. S.A. Isayev, N.I. Vatin, V.A. Lebiga, V.N. Zinoviev, Ch. Ke-Chin, M. Tszyun-Ji

23. Engineering and construction magazine, 2(37) 2013

24. 23 M. Lazarevska, M. Cvetkovska, M. Knezevic, A.T. Gavriloska, M. Milanovic, V. Murgul, N. Vatin, Applied mechanics and materials, 627 (2014)

25. Kostić Radinko, Vatin Nikolay, Murgul Vera, Applied Mechanics and Materials, 725726 (2015)

26. Lukasz Zdanowicz., P. Kisiel, A. Kwiecień, Procedia Engineering, 108 (2015)

27. JV 13.13130.2009 Nuclear power plants. Fire safety requirements (with Change No. 1)

28. S. Rinaldi, A Flammini, M. Pasetti, L. C. Tagliabue, A. C. Ciribini, S. Zanoni, 2018 IEEE International Instrumentation and Measurement Technology Conference (I2MTC), 14-17 May 2018, Houston, Texas, USA (2018). DOI: 10.1109/I2MTC.2018.8409740 